\title{
Nutrition, Metabolism, and Fertility in Dairy Cows: 2. Dietary Fatty Acids and Ovarian Function
}

\author{
P. C. Garnsworthy, ${ }^{1}$ A. Lock, ${ }^{2}$ G. E. Mann, K. D. Sinclair, and R. Webb \\ University of Nottingham, School of Biosciences, Sutton Bonington Campus, Loughborough LE12 5RD, UK
}

\begin{abstract}
Plasma insulin has important implications for ovarian function in dairy cows. Previous work demonstrated that plasma insulin increased with increasing dietary starch and decreasing dietary fatty acid concentrations. The objective of this experiment was to investigate hormonal and ovarian responses to dietary fatty acid content with no change in other dietary components. Thirty cows were fed a standard diet from calving until $40 \mathrm{~d}$ in milk (DIM) and then 6 cows were transferred to each of 5 diets containing $0,8,15,23$, and $30 \mathrm{~g} / \mathrm{kg}$ of dry matter (DM) of calcium salts of palm fatty acids (CaPFA; Megalac) until 70 DIM. Estrus was synchronized at 60 DIM. Between 60 and 70 DIM, energy intake, milk yield, and energy balance were similar among diet groups. Plasma insulin decreased when dietary concentration of CaPFA exceeded $15 \mathrm{~g} / \mathrm{kg}$ of DM (insulin: 0.46, 0.41, 0.46, 0.33, $0.28 \pm \mathrm{SE} 0.034$ $\mathrm{ng} / \mathrm{mL}$ for diets containing 0 to $30 \mathrm{~g}$ of $\mathrm{CaPFA} / \mathrm{kg}$ of $\mathrm{DM}$, respectively). Maximum plasma insulin to glucagon ratio was observed with $15 \mathrm{~g}$ of $\mathrm{CaPFA} / \mathrm{kg}$ of $\mathrm{DM}$ (ratios: 3.99, 4.33, 4.67, 3.45, $2.89 \pm \mathrm{SE} 0.156$ for diets containing 0 to $30 \mathrm{~g}$ of $\mathrm{CaPFA} / \mathrm{kg}$ of $\mathrm{DM}$, respectively). Plasma concentrations of growth hormone, insulin-like growth factor-I and leptin did not vary between diets. The number of small $(<5 \mathrm{~mm})$ ovarian follicles was negatively related to plasma insulin concentration $(\mathrm{r}$ $=-0.328$ ) and was stimulated by CaPFA supplementation at all rates tested compared with cows receiving zero CaPFA (small follicles preovulation: 6.7, 11.2, $11.5,11.3,11.9 \pm \mathrm{SE} 1.48$ for diets containing 0 to 30 $\mathrm{g}$ of $\mathrm{CaPFA} / \mathrm{kg}$ of DM, respectively). The number of medium-sized follicles, and diameters of the ovulatory follicles and corpora lutea, were not affected by CaPFA supplementation. It is concluded that dietary total fat
\end{abstract}

\footnotetext{
Received January 18, 2008.

Accepted May 29, 2008.

${ }^{1}$ Corresponding author: Phil.Garnsworthy@nottingham.ac.uk

${ }^{2}$ Present address: Department of Animal Science, University of Vermont, Burlington 05405.
}

concentration should be below $50 \mathrm{~g} / \mathrm{kg}$ of DM to avoid depressing plasma insulin concentration in cows at the start of the breeding period.

Key words: dairy cow, insulin, fatty acid, ovarian function

\section{INTRODUCTION}

Metabolic hormones influence dairy cow fertility by interacting with reproductive hormones that control ovarian function and reproductive events (Webb et al., 2004; Garnsworthy et al., 2008b). Genetic selection of dairy cows for high milk production was associated with a longer interval from parturition to first ovulation, high plasma concentrations of growth hormone (GH) and BHBA, and low plasma concentrations of glucose and insulin (Gutierrez et al., 2006). These effects can often be attributed to prolonged periods of negative energy balance in cows of high genetic merit (Garnsworthy et al., 2008b). Feeding a diet to increase circulating insulin concentrations for the first 50 DIM increased the proportion of dairy cows ovulating during this period (Gong et al., 2002). The effect was observed in cows of both high and low genetic merit and was not associated with milk yield or energy balance. Because insulin is affected by many dietary and animal factors, it is desirable to explore different approaches to insulin manipulation so that optimum strategies can be developed to improve reproductive performance.

In Garnsworthy et al. (2008a), plasma insulin decreased as the main supplementary energy source was changed from starch to fatty acids in isoenergetic diets. The number of small ovarian follicles was positively related to plasma insulin concentration. Because both starch and fatty acids can influence insulin, further work is needed to separate their effects in relation to metabolic hormones and ovarian function. The objective reported here was to investigate responses to dietary fatty acid supplementation with no substantial change in other dietary components. In addition to metabolic hormones and indicators of ovarian function (follicle dynamics and steroid hormones), responses in milk production and plasma metabolites are reported. 
Table 1. Formulation and chemical composition of treatment diets containing 5 levels of supplemental fatty acids

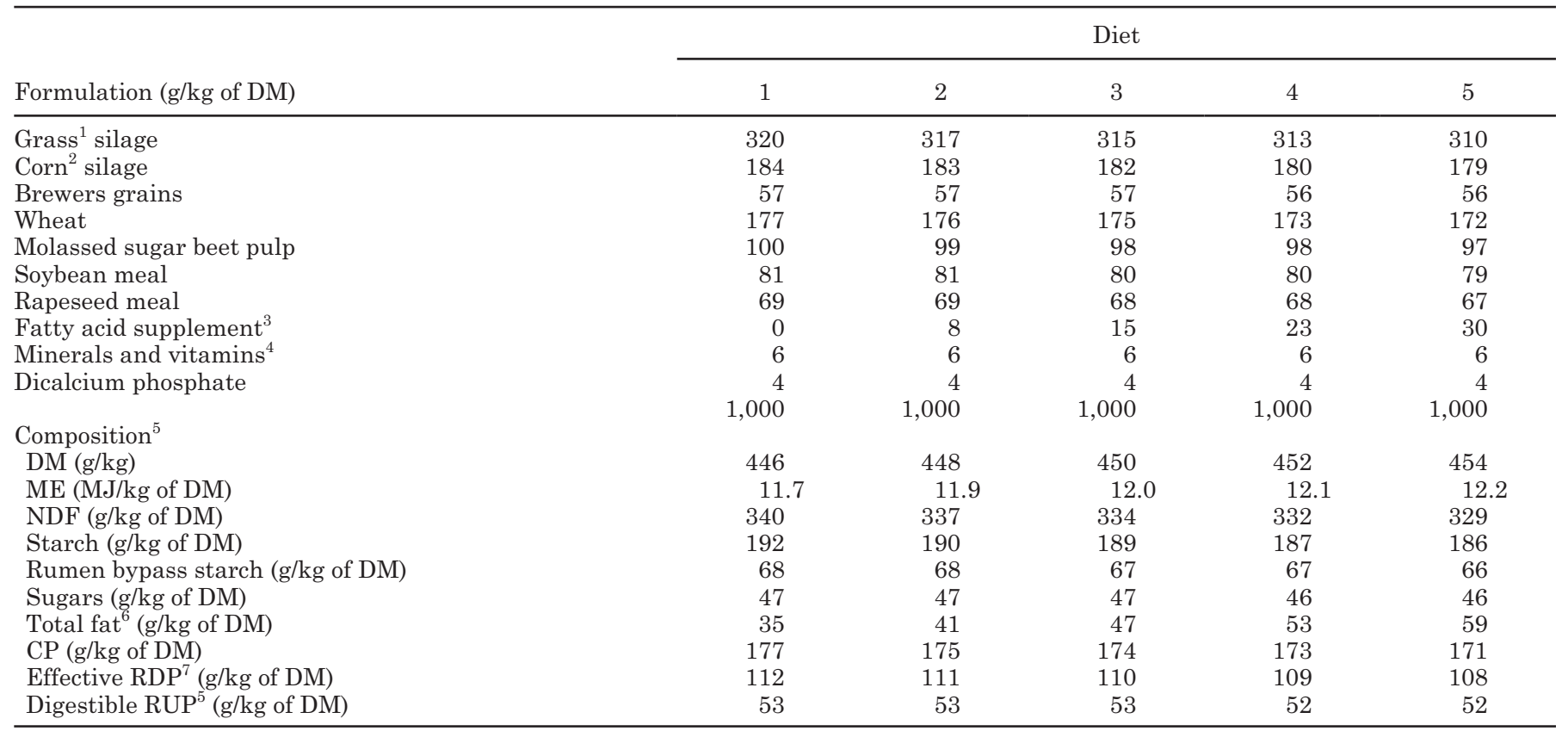

${ }^{1}$ Perennial ryegrass (Lolium perenne).

${ }^{2}$ Maize (Zea mays).

${ }^{3}$ Megalac (calcium salts of palm fatty acids): Volac International, Royston, UK.

${ }^{4}$ Bibby HiPhos: ABN Ltd., Peterborough, UK: calcium, 18\%; phosphorus, 10\%; magnesium, 5\%; salt, 17\%; copper, $2000 \mathrm{mg} / \mathrm{kg}$; manganese, $5,000 \mathrm{mg} / \mathrm{kg}$; cobalt, $100 \mathrm{mg} / \mathrm{kg}$; zinc, $6,000 \mathrm{mg} / \mathrm{kg}$; iodine, $500 \mathrm{mg} / \mathrm{kg}$; selenium, $25 \mathrm{mg} / \mathrm{kg}$; vitamin A, 400,000 IU $/ \mathrm{kg}$; vitamin $\mathrm{D}_{3}, 80,000$ IU/ $\mathrm{kg}$; vitamin E, 1,000 mg/kg.

${ }^{5}$ Calculated from laboratory analysis of components.

${ }^{6}$ Acid hydrolysis method.

${ }^{7}$ Calculated from rumen degradability values determined in situ and laboratory analysis of components.

\section{MATERIALS AND METHODS}

\section{Animals, Management, and Diets}

Thirty multiparous Holstein dairy cows were grouphoused and individually fed through Calan electronic gates from calving until 70 DIM. Diets were fed as TMR and daily feed allowances were adjusted for each cow to at least $110 \%$ of intake to ensure true ad libitum feeding (Garnsworthy et al., 2008a).

Cows were fed a standard TMR (diet 2; Table 1) from calving until 35 DIM and were assigned to 6 blocks of 5 cows on the basis of calving date. Blocks were matched for milk yield recorded during the first 20 DIM. From 35 DIM, cows were transferred at random within blocks to 5 treatment TMR over a period of $5 \mathrm{~d}$. Treatment TMR were fed from 40 to 70 DIM. For logistical reasons (to synchronize groups of cows for hourly blood sampling sessions), the final day of treatment (70 DIM) was adjusted by 0 to $3 \mathrm{~d}$ for each cow, and all preceding treatment and sampling days were adjusted by the same amount. The mean final day of treatment was $69.6( \pm$ SE 0.34) DIM.
Treatment TMR (Table 1) were based on diet 2 from Garnsworthy et al. (2008a), which was formulated to supply ME and MP requirements for $45 \mathrm{~L}$ of milk production, with a starch content of $190 \mathrm{~g} / \mathrm{kg}$ of DM and a total fat content of $42 \mathrm{~g} / \mathrm{kg}$ of DM. The 5 TMR were produced by adjusting supplemental fatty acids (CaPFA; calcium salts of palm fatty acids) to give concentrations of $0,8,15,23$, and $30 \mathrm{~g}$ of CaPFA/kg of DM, which would supply predicted intakes of $0,0.2,0.4,0.6$, and $0.8 \mathrm{~kg}$ of $\mathrm{CaPFA} / \mathrm{d}$.

\section{Feed Analysis}

Food intake was recorded daily, and samples of diet ingredients and mixed TMR were taken for analysis at weekly intervals (Garnsworthy et al., 2008a).

\section{Estrous Synchronization}

Estrous cycles were synchronized to 60 DIM when cows were allowed to ovulate without further hormonal intervention (Garnsworthy et al., 2008a). Ovarian activity was monitored by daily transrectal ultrasound 
Table 2. Least squares means over 60 to 70 DIM, adjusted by covariance for values between 30 and 35 DIM, for intakes, milk production and composition, BW, and BCS in cows $(n=6)$ given diets containing 5 levels of supplemental fatty acids

\begin{tabular}{|c|c|c|c|c|c|c|c|c|c|}
\hline \multirow[b]{2}{*}{ Item } & \multicolumn{5}{|c|}{ Fatty acid supplementation (g/kg of DM) } & \multirow[b]{2}{*}{$\mathrm{SED}^{1}$} & \multicolumn{3}{|c|}{ Contrast $^{2}$} \\
\hline & 0 & 8 & 15 & 23 & 30 & & Diet & Linear & Quadratic \\
\hline \multicolumn{10}{|l|}{ Intake of } \\
\hline $\mathrm{DM}(\mathrm{kg} / \mathrm{d})$ & 21.8 & 22.8 & 21.7 & 22.5 & 22.0 & 0.91 & 0.732 & 0.957 & 0.624 \\
\hline Starch $(\mathrm{kg} / \mathrm{d})$ & 4.2 & 4.3 & 4.1 & 4.2 & 4.1 & 0.17 & 0.657 & 0.423 & 0.650 \\
\hline Sugars (kg/d) & 0.92 & 0.98 & 0.94 & 0.97 & 0.92 & 0.039 & 0.406 & 0.954 & 0.187 \\
\hline $\mathrm{NDF}(\mathrm{kg} / \mathrm{d})$ & 7.4 & 7.7 & 7.3 & 7.5 & 7.2 & 0.30 & 0.620 & 0.452 & 0.560 \\
\hline Total fat (kg/d) & $0.76^{\mathrm{a}}$ & $0.94^{\mathrm{b}}$ & $1.03^{\mathrm{b}}$ & $1.20^{\mathrm{c}}$ & $1.30^{\mathrm{d}}$ & 0.046 & $<0.001$ & $<0.001$ & 0.682 \\
\hline $\mathrm{ME}(\mathrm{MJ} / \mathrm{d})$ & 257 & 271 & 261 & 273 & 270 & 10.9 & 0.551 & 0.268 & 0.744 \\
\hline \multicolumn{10}{|l|}{ Milk production } \\
\hline Milk yield (kg/d) & 40.5 & 41.9 & 39.1 & 41.6 & 40.9 & 1.55 & 0.525 & 0.632 & 0.308 \\
\hline $\mathrm{FCM}^{3}(\mathrm{~kg} / \mathrm{d})$ & 41.0 & 42.7 & 42.2 & 43.9 & 43.6 & 2.35 & 0.753 & 0.244 & 0.776 \\
\hline Milk fat $(\mathrm{g} / \mathrm{kg})$ & 35.7 & 36.3 & 39.9 & 38.2 & 38.9 & 1.44 & 0.230 & 0.079 & 0.354 \\
\hline$(\mathrm{g} / \mathrm{d})$ & 1,443 & 1,515 & 1,556 & 1,595 & 1,591 & 71.4 & 0.552 & 0.108 & 0.581 \\
\hline Milk protein (g/kg) & 29.2 & 29.6 & 29.2 & 29.2 & 29.6 & 0.54 & 0.961 & 0.843 & 0.816 \\
\hline$(g / d)$ & 1,183 & 1,238 & 1,142 & 1,212 & 1,212 & 44.4 & 0.612 & 0.822 & 0.738 \\
\hline Milk lactose (g/kg) & 45.8 & 45.5 & 45.5 & 46.7 & 46.7 & 0.48 & 0.211 & 0.169 & 0.297 \\
\hline$(g / d)$ & 1,858 & 1,908 & 1,782 & 1,945 & 1,914 & 81.2 & 0.656 & 0.570 & 0.682 \\
\hline Energy balance $(\mathrm{MJ} / \mathrm{d})$ & 3.1 & 2.1 & 4.1 & 2.8 & 3.3 & 5.55 & 0.745 & 0.567 & 0.887 \\
\hline \multicolumn{10}{|l|}{ Weight and condition } \\
\hline BW (kg) & 606 & 598 & 612 & 644 & 620 & 19.8 & 0.531 & 0.244 & 0.889 \\
\hline BW change $(\mathrm{kg} / \mathrm{d})$ & -0.07 & 0.38 & 0.13 & -0.45 & 0.18 & 0.184 & 0.136 & 0.569 & 0.992 \\
\hline BCS & 2.6 & 2.8 & 2.6 & 2.9 & 2.8 & 0.25 & 0.914 & 0.606 & 0.998 \\
\hline BCS change & 0.12 & -0.05 & -0.38 & -0.46 & -0.27 & 0.239 & 0.112 & 0.032 & 0.134 \\
\hline
\end{tabular}

${ }^{a-d}$ Means in the same row without a common superscript differ $(P<0.05)$.

${ }^{1} \mathrm{SED}=$ standard error of the difference between treatment means.

${ }^{2}$ Probability of diet effect, and linear and quadratic effects of level of supplemental fatty acids.

${ }^{3} 3.5 \% \mathrm{FCM}$ yield $=$ milk yield $\times\{0.425+[16.425 \times$ Milk fat $(\mathrm{g} / \mathrm{kg}) / 1,000]\}$. 
scanning from 61 to 70 DIM (Garnsworthy et al., 2008a).

\section{Performance Measurements}

Milk yield was recorded daily from calving until 70 DIM. Milk samples were collected from daily milkings at 30 and 35 DIM, and each day from 60 to 70 DIM, and analyzed for fat, protein, and lactose contents (Garnsworthy et al., 2008a). Body weight and BCS were recorded weekly from 30 to 70 DIM (Garnsworthy et al., 2008a).

\section{Blood Sampling}

Blood samples were collected by jugular venipunc-

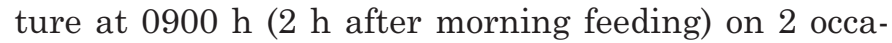
sions between 30 and 35 DIM for determination of base-line values of hormones and metabolites. Further blood samples were collected from 60 to 70 DIM for determination of daily variation in hormones and metabolites (Garnsworthy et al., 2008a). Blood samples were analyzed for insulin, GH, IGF-I, glucagon, leptin, estradiol, progesterone, albumin, total protein, globulin (total protein minus albumin), urea-N, glucose, BHBA, NEFA, magnesium, and inorganic phosphorus (Garnsworthy et al., 2008a).

\section{Statistical Analyses}

Metabolizable energy balance was calculated for each cow from BW, milk energy output, and metabolizable energy intake, using UPWin software (AGM Systems, Exeter, UK) and feed into milk equations (Garnsworthy et al., 2008a).

Dietary effects on mean performance and blood data during the treatment period (60 to 70 DIM) were examined by analysis of covariance, using Genstat 8 (Lawes Agricultural Trust, Rothamsted, UK), looking at the main effect of dietary treatment group, with observations during the standardization period (30 to 35 DIM) as covariates. When the main effect was significant, differences among treatment means were tested by least significant difference. Linear, quadratic, and cubic effects of level of CaPFA supplementation were examined, although because no significant cubic effect was found this contrast was removed from the analysis. Simple correlation coefficients were determined to examine relationships among variates. The all-subsets regression procedure (Genstat 8, Lawes Agricultural Trust) was used to identify significant multiple relationships among variates, and coefficients for these were determined by multiple linear regression (Garnsworthy et al., 2008a).
Reproductive data were analyzed by using generalized linear models with a Poisson distribution and log link function. For progesterone, estradiol, ovulatory follicle diameter, and corpus luteum diameter, day of ovulation was included as a covariate (Garnsworthy et al., 2008a).

The power of the experimental design was calculated for selected measurements from the residual mean squares provided by the analysis of covariance. Although the level of replication (6 cows per diet) can make it difficult to detect differences between diets for some more variable measures, this is offset by a greater power to detect linear and quadratic responses to level of fatty acids. Taking NEFA (the most variable plasma metabolite) as an example, the probability of detecting a true significant difference (power of test) between the treatment groups with the highest and lowest means was $67 \%$, but the probability of detecting a true linear response was $85 \%$ (power $>80 \%$ was considered sufficient). The primary focus of this study was on insulin, for which the power was $95 \%$ for testing differences between groups and $98 \%$ for testing responses.

\section{RESULTS}

\section{Intake, Milk Production, and Body Weight}

Intakes of DM, starch, sugars, NDF, and ME did not vary between treatment groups (Table 2). Total fat intake increased linearly $(P<0.001)$ with increasing level of CaPFA supplementation.

Milk yield, 3.5\% FCM, milk composition, energy balance, BW, BW change, BCS, and change in BCS did not vary between treatment groups, but milk fat content tended to increase linearly $(P=0.079)$ with increasing level of CaPFA supplementation (Table 2). There was a negative linear relationship between change in BCS and level of CaPFA supplementation.

\section{Metabolic Hormones and Metabolites}

Mean plasma insulin concentration varied $(P<0.001)$ among treatment groups (Table 3 ), with significant linear $(P<0.001)$ and quadratic $(P<0.05)$ effects of level of CaPFA supplementation. Insulin was less in cows fed fatty acid supplementation at 23 and $30 \mathrm{~g} / \mathrm{kg}$ of DM than in cows fed other diets. There was no difference between treatment groups in mean plasma glucagon, but the insulin to glucagon ratio was higher at 0,8 , and $15 \mathrm{~g} / \mathrm{kg}$ of DM of CaPFA supplementation than 30 $\mathrm{g} / \mathrm{kg}$ of CaPFA supplementation, with significant $(P$ $<0.05$ ) linear and quadratic effects of level of CaPFA supplementation. For IGF-I, GH, and leptin, there was no difference between treatment groups. There was no 
Table 3. Least squares means over 60 to 70 DIM, adjusted by covariance for values between 30 and 35 DIM, for plasma concentrations of metabolic hormones and metabolites in cows $(n=6)$ given diets containing 5 levels of supplemental fatty acids

\begin{tabular}{|c|c|c|c|c|c|c|c|c|c|}
\hline \multirow[b]{2}{*}{ Item } & \multicolumn{5}{|c|}{ Fatty acid supplementation (g/kg of DM) } & \multirow[b]{2}{*}{$\mathrm{SED}^{1}$} & \multicolumn{3}{|c|}{ Contrast $^{2}$} \\
\hline & 0 & 8 & 15 & 23 & 30 & & Diet & Linear & Quadratic \\
\hline Glucagon $(\mathrm{pg} / \mathrm{mL})$ & 106 & 104 & 102 & 95 & 102 & 5.9 & 0.427 & 0.380 & 0.745 \\
\hline Insulin:glucagon ratio & $3.99^{\mathrm{bc}}$ & $4.33^{\mathrm{bc}}$ & $4.67^{\mathrm{c}}$ & $3.45^{\mathrm{ab}}$ & $2.89^{\mathrm{a}}$ & 0.221 & 0.027 & 0.018 & 0.043 \\
\hline IGF-I (ng/mL) & 121 & 126 & 111 & 118 & 99 & 12.1 & 0.568 & 0.191 & 0.577 \\
\hline Growth hormone (ng/mL) & 10.5 & 11.4 & 10.1 & 11.5 & 11.5 & 1.50 & 0.776 & 0.465 & 0.845 \\
\hline Globulin (g/L) & 39.5 & 33.7 & 38.8 & 39.0 & 37.5 & 2.43 & 0.457 & 0.866 & 0.657 \\
\hline Total protein (g/L) & 73.7 & 68.1 & 75.6 & 72.4 & 72.7 & 3.12 & 0.550 & 0.825 & 0.913 \\
\hline Urea-N (mmol/L) & 3.10 & 2.88 & 2.68 & 2.75 & 2.65 & 0.181 & 0.403 & 0.082 & 0.462 \\
\hline $\mathrm{BHBA}(\mathrm{mmol} / \mathrm{L})$ & 0.47 & 0.67 & 0.60 & 0.62 & 0.59 & 0.064 & 0.287 & 0.350 & 0.133 \\
\hline NEFA (mmol/L) & 0.11 & 0.11 & 0.13 & 0.14 & 0.16 & 0.026 & 0.307 & 0.048 & 0.996 \\
\hline Glucose $(\mathrm{mmol} / \mathrm{L})$ & 3.32 & 3.06 & 3.09 & 3.34 & 3.18 & 0.096 & 0.154 & 0.952 & 0.251 \\
\hline Phosphorus (mmol/L) & 1.48 & 1.41 & 1.53 & 1.42 & 1.40 & 0.066 & 0.588 & 0.453 & 0.561 \\
\hline
\end{tabular}

${ }^{a-c}$ Means in the same row without a common superscript differ $(P<0.05)$.

${ }^{1} \mathrm{SED}=$ standard error of the difference between treatment means.

${ }^{2}$ Probability of diet effect, and linear and quadratic effects of level of supplemental fatty acids.

difference between treatment groups for plasma concentrations of albumin, globulin, total protein, glucose, BHBA, phosphorus, or magnesium (Table 3). There was no difference between treatment groups for NEFA or urea-N, but level of CaPFA supplementation had a positive linear effect on NEFA $(P<0.05)$.

\section{Ovarian Activity}

Ovulation was detected by ultrasound scanning in all 30 cows. Mean $( \pm$ SE) day of ovulation was $4.2 \pm 0.3$ (range 2 to 9) $d$ after synchronization. Two cows (one fed diet 1 and one fed diet 4) did not ovulate until d 9 of the 10-d scanning period. It was not possible to include postovulatory data from these 2 cows for follicle numbers, corpus luteum (CL) diameter, and progesterone.

The maximum number of small $(<5 \mathrm{~mm})$ follicles during the preovulatory and postovulatory waves, from d 3 to 5 postovulation were lower in diet group 1 (no supplementary fatty acids) than in the other groups (Table 4). Plasma progesterone was different between diet groups 1 and 3 and 4 .

There was no difference between treatment groups in number of medium-sized (5 to $10 \mathrm{~mm}$ ) follicles during the postovulatory wave, maximum diameter of the ovulatory follicle, maximum diameter of the CL that developed postovulation, or mean plasma estradiol during the preovulatory phase ( $\mathrm{d}-2$ to 0 ; Table 4$)$.

\section{Relationships Among Variables (Across Individuals)}

Plasma insulin was positively correlated with dietary starch concentration $(r=0.467)$ and plasma leptin $(r$ $=0.403)$. Insulin was negatively correlated with total dietary fat concentration $(\mathrm{r}=-0.471)$, milk lactose concentration $(r=-0.607)$, lactose yield $(r=-0.434)$, and plasma NEFA ( $r=-0.378)$. Plasma IGF-I was positively correlated with BCS $(\mathrm{r}=0.427)$ and plasma urea-N $(\mathrm{r}=$ $0.383)$, and negatively correlated with GH $(r=-0.644)$. Plasma leptin was negatively correlated with yields of milk $(\mathrm{r}=-0.457)$, protein $(\mathrm{r}=-0.438)$, lactose $(\mathrm{r}=$ $-0.503)$, milk lactose concentration $(\mathrm{r}=-0.388)$, and $\mathrm{GH}(\mathrm{r}=-0.448)$, and positively correlated with BHBA $(r=0.412)$. None of the measures was correlated with glucagon.

The maximum number of small $(<5 \mathrm{~mm})$ ovarian follicles during the follicular wave preceding ovulation was positively related to milk yield, total fat intake, and $\mathrm{GH}$, and negatively related to milk protein concentration, leptin, and insulin (Table 5). Similar relationships were observed during the first follicular wave postovulation, plus additional positive relationships with DMI and energy balance.

The best multiple regression equation for predicting plasma insulin concentration included a negative curvilinear effect of total dietary fat concentration and a positive effect of BW (Table 6). This equation accounted for $33 \%$ of variation in plasma insulin. The best mul- 
Table 4. Treatment means ${ }^{1}$ before and after a synchronized estrus at around 60 DIM for plasma concentrations of estradiol before ovulation and progesterone from d 3 to 5 postovulation, as well as follicle numbers, ovulatory follicle diameter, and corpus luteum (CL) diameter in cows $(n=6)$ given diets containing 5 levels of supplemental fatty acids

\begin{tabular}{|c|c|c|c|c|c|c|c|c|c|}
\hline Item & \multicolumn{5}{|c|}{ Fatty acid supplementation ( $\mathrm{g} / \mathrm{kg}$ of $\mathrm{DM})$} & $\mathrm{SED}^{2}$ & \multicolumn{3}{|c|}{ Contrast $^{3}$} \\
\hline Progesterone (ng/mL) & $2.9^{\mathrm{a}}$ & $3.7^{\mathrm{ab}}$ & $3.8^{\mathrm{ab}}$ & $4.8^{\mathrm{b}}$ & $4.7^{\mathrm{b}}$ & 0.77 & 0.038 & 0.036 & 0.241 \\
\hline \multicolumn{10}{|l|}{ Small follicles $(<5 \mathrm{~mm})$} \\
\hline Maximum preovulation & $6.7^{\mathrm{a}}$ & $11.2^{\mathrm{b}}$ & $11.5^{\mathrm{b}}$ & $11.3^{\mathrm{b}}$ & $11.9^{\mathrm{b}}$ & 2.10 & 0.006 & 0.015 & 0.015 \\
\hline Mean postovulation & 7.9 & 9.6 & 7.9 & 9.3 & 8.9 & 2.57 & 0.932 & 0.688 & 0.622 \\
\hline Mean postovulation & 2.6 & 2.8 & 2.7 & 2.8 & 2.7 & 0.82 & 0.996 & 0.850 & 0.938 \\
\hline Maximum postovulation & 4.5 & 4.3 & 4.7 & 4.8 & 5.0 & 1.66 & 0.986 & 0.549 & 0.776 \\
\hline Ovulatory follicle diameter $(\mathrm{mm})$ & 21 & 21 & 20 & 22 & 21 & 2.7 & 0.881 & 0.828 & 0.847 \\
\hline CL diameter ${ }^{4}(\mathrm{~mm})$ & 26 & 30 & 29 & 29 & 31 & 3.6 & 0.625 & 0.186 & 0.517 \\
\hline Day of ovulation & 4.7 & 3.7 & 3.5 & 5.2 & 4.2 & 0.92 & 0.365 & 0.810 & 0.429 \\
\hline
\end{tabular}

${ }^{a-c}$ Means in the same row without a common superscript differ $(P<0.05)$.

${ }^{1}$ Values are back-transformed from generalized linear models with Poisson distribution and log link function. For progesterone, estradiol, ovulatory follicle diameter, and CL diameter, day of ovulation was included as a covariate.

${ }^{2} \mathrm{SED}=$ standard error of the difference between treatment means.

${ }^{3}$ Probability of diet effect, and linear and quadratic effects of level of supplemental fatty acids.

${ }^{4}$ On d 5 following ovulation.

tiple regression equation for predicting plasma IGF-I concentration included positive effects of BCS and a negative effect of total dietary fat concentration. This equation accounted for $22 \%$ of variation in plasma IGFI. The best regression equation for predicting plasma leptin concentration included only a negative effect of milk yield. This equation accounted for $18 \%$ of variation in plasma leptin.

\section{DISCUSSION}

The main hypothesis of the current experiment was that plasma insulin concentration would be influenced by level of CaPFA supplementation. This hypothesis was supported by the differences in insulin observed among treatments and the negative relationship between insulin and total fat intake. Garnsworthy et al. (2008a) found plasma insulin decreased when cows were fed isoenergetic diets changing from high starch to high fat. Effects of changes in dietary starch and fat concentrations could not be separated in that experiment; however, the current experiment quantifies responses to changing concentrations of dietary fatty acids, whereas proportions of all other dietary components remained substantially constant.

The negative relationship between CaPFA supplementation and plasma insulin was quadratic; plasma insulin decreased when dietary concentration of CaPFA exceeded $15 \mathrm{~g} / \mathrm{kg}$ of DM. Choi and Palmquist (1996) reported a linear decrease in insulin with increasing fatty acid supplementation, which they attributed to stimulation of cholecystokinin and pancreatic polypeptide release, accompanied by reductions in DMI. Subsequently, Choi et al. (2000) used a cholecystokinin antagonist to reverse the fat-induced depression in DMI and found that insulin was still decreased by a high fat diet. This is consistent with results of the current experiment, where the 2 highest levels of CaPFA supplementation $(\geq 23 \mathrm{~g}$ of $\mathrm{CaPFA} / \mathrm{kg}$ of $\mathrm{DM})$ decreased insulin without a depression in DMI.

Allen (2000) found that CaPFA supplementation significantly decreased DMI in 11 of 24 comparisons. A negative effect of increasing CaPFA on DMI in the current experiment might have been anticipated. The most likely explanation for the difference is that in the majority of studies reviewed by Allen (2000) CaPFA replaced a proportion of grain in diets, thereby reducing fermentable ME content, and theoretically slowing rumen fermentation. In the current study, CaPFA was added to a high-starch basal TMR, so diet 5 had $69 \%$ higher fat concentration, but only $3 \%$ lower starch concentration than diet 1 . A second contributory factor could be incorporation of CaPFA into TMR instead of into separately fed concentrates or top-dressing CaPFA onto the forage portion of the diet, thus mitigating any acceptability effects of CaPFA (Allen, 2000). A third factor could be that Allen (2000) included cows in late lactation, cows with low milk production, and abnormally high levels of added fat (up to $6.2 \%$ added fatty acids, and $9 \%$ total fatty acids); cows with lower energy 


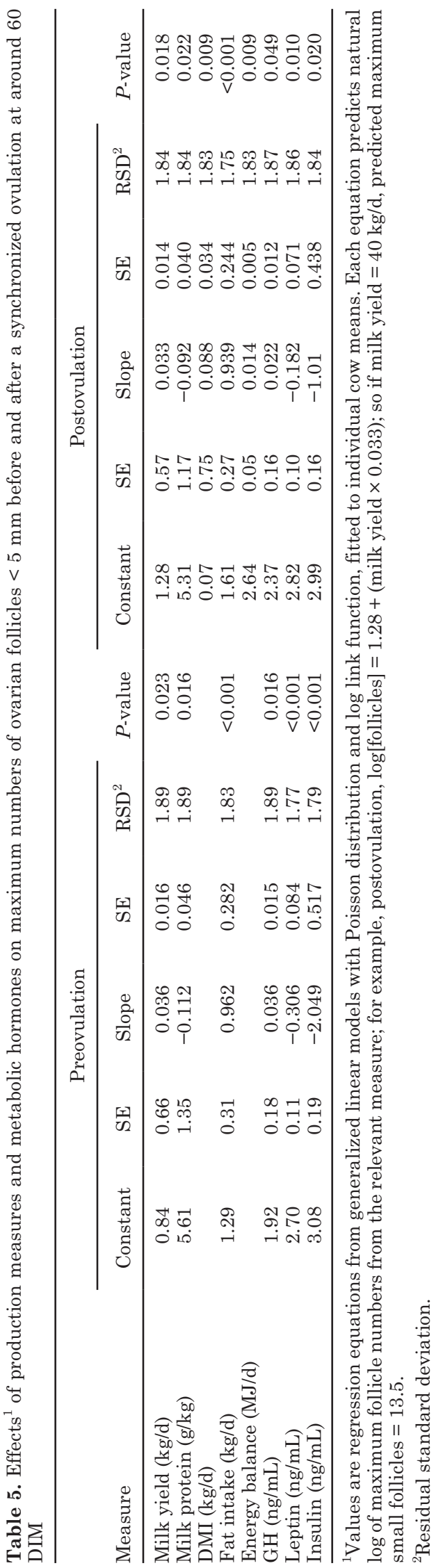

requirements would be expected to show a greater reduction in DMI as dietary energy concentration increases, particularly with levels of fat supplementation that are more than double the manufacturers' recommendations.

The design of this experiment allows examination of responses to diets varying widely in fatty acid content across the range found in normal commercial practice. An advantage of providing stepped changes in fatty acid supplementation was that intermediate responses can indicate thresholds. The quadratic response of insulin to level of CaPFA supplementation suggests that insulin secretion was reduced at high dietary fatty acid concentrations and that the break point was approximately $50 \mathrm{~g}$ of total fat $/ \mathrm{kg}$ of DM (20 g of CaPFA $/ \mathrm{kg}$ of DM). This is slightly higher than the break point in our previous study (43 g of total fat/kg of DM; Garnsworthy et al., 2008a), suggesting that reducing starch concentration influenced insulin in addition to the effect of increasing fatty acid concentration. The range of dietary fat concentrations in the studies of Choi and Palmquist (1996) and Choi et al. (2000; 27 to $89 \mathrm{~g}$ of total fatty acids/kg of DM) was greater than in the current study, but in both studies insulin was lower with $60 \mathrm{~g}$ of $\mathrm{CaPFA} / \mathrm{kg}$ of DM compared with $30 \mathrm{~g}$ of $\mathrm{CaPFA} / \mathrm{kg}$ of DM, supported by the current study. The manufacturer's recommended feeding rate for Megalac CaPFA is 0.5 to $0.75 \mathrm{~kg} / \mathrm{d}$ (Volac International Ltd.; http://www.volac.com), which covers the range provided by diets 3 to 5. Many nutritionists recommend a maximum supplementation rate for CaPFA of 0.5 $\mathrm{kg} / \mathrm{d}$ or $22 \mathrm{~g} / \mathrm{kg}$ of ration DM in commercial practice (Jenkins, 2003), which was supported by the insulin responses observed in the current study. This would make diet 4 the maximum recommendation, and diet 5 would exceed it.

Glucagon was not significantly affected by diet, in contrast to Garnsworthy et al. (2008a), where glucagon varied with dietary fat and starch concentrations; this suggests that low dietary starch concentration might be a greater stimulus for glucagon secretion than high dietary fat concentration. Insulin to glucagon ratio showed a curvilinear response to increasing dietary fatty acid supplementation, reaching a breaking point between 15 and $23 \mathrm{~g}$ of $\mathrm{CaPFA} / \mathrm{kg}$ of DM. In contrast, this level of fatty acid supplementation produced the lowest insulin to glucagon ratio in Garnsworthy et al. (2008a), suggesting that the ratio is influenced more by dietary starch than dietary fatty acid concentration.

As in our previous experiment (Garnsworthy et al., 2008a), IGF-I, GH, and leptin did not vary between diets. In contrast to the previous experiment, negative relationships were found between GH and IGF-I, and between GH and leptin. It would appear that these re- 
Table 6. Best regression equations to predict metabolic hormones from intake, milk production, BW, BCS, and blood measures

\begin{tabular}{|c|c|c|c|c|c|c|}
\hline Item & Constant & Slope 1 & Slope 2 & Slope 3 & $\mathrm{RSD}^{1}$ & $\% \mathrm{VAR}^{2}$ \\
\hline \multicolumn{7}{|l|}{ Insulin (ng/mL) } \\
\hline Diet fat $\left(\mathrm{g} / \mathrm{kg}\right.$ of DM) $+\operatorname{Diet~fat~}^{2}(\mathrm{~g} / \mathrm{kg}$ of $\mathrm{DM})+\mathrm{BW}(\mathrm{kg})$ & -1.2 & 0.054 & -0.00065 & 0.00082 & 0.10 & 32.9 \\
\hline \multicolumn{7}{|l|}{ IGF-I (ng/mL) } \\
\hline \multicolumn{7}{|l|}{ Leptin $(\mathrm{ng} / \mathrm{mL})$} \\
\hline Milk yield (kg/d) & 5.12 & -0.095 & & & 0.68 & 18.0 \\
\hline
\end{tabular}

${ }^{1}$ Residual standard deviation.

${ }^{2}$ Percentage of variation accounted for by regression equation.

lationships were due to normal physiological relationships among metabolic hormones rather than direct influence of dietary manipulation.

There was no difference between treatments in the average number of small or medium-sized follicles. It has to be recognized that the average number of follicles in each size class on a particular scanning day is the net result of the processes of follicle recruitment, growth, and atresia. Because these processes progress at different rates among individual cows (Burns et al., 2005), follicular waves will not be synchronized between cows, even after data are aligned to day of ovulation. For this reason, maximum numbers of small and medium-sized follicles per individual cow give a better indication of potential follicular pools available for selection. Maximum numbers of follicles are repeatable within cows, and there is some evidence that they are related to circulating concentrations of FSH and inhibin (Burns et al., 2005). Fatty acid supplementation stimulated maximum numbers of small follicles at all levels tested, compared with the zero level of CaPFA supplementation, and insulin was negatively related ( $\mathrm{r}$ $=-0.328$ ) to maximum number of small follicles across individual cows. This contrasts with Garnsworthy et al. (2008a), where maximum number of small follicles was decreased by high dietary fatty acid concentrations and was positively related to insulin. Similar results were observed by Lucy et al. (1991b), where the average number of small follicles was decreased by fatty acid supplementation over the first 25 DIM, but increased during and after progesterone treatment. Discrepancies among studies probably result from differential effects of energy balance, insulin, fatty acids, and other factors on recruitment, growth, and atresia of small follicles. For example, some studies have reported positive effects of insulin on numbers of small (Gutierrez et al., 1997), medium-sized (Oldick et al., 1997), or large (Lucy et al., 1991a) follicles; others have reported positive effects of fat supplementation (Lucy et al., 1991b; Beam and Butler, 1997) on numbers of large follicles. In a review of follicular dynamics in cattle, Lucy et al. (1992) concluded that CaPFA themselves, and not the additional energy provided by CaPFA, stimulated the ovary and enhanced movement of follicles to larger classes. Taken together, these reports suggest that both fatty acid supply and insulin have minimum thresholds, so increasing either factor would stimulate follicle development only when the other is adequate. From the results of the current study, it could be concluded that fatty acid supply for diet 1 was suboptimal for recruitment of small follicles, despite an adequate insulin concentration for this treatment; both fatty acid supply and insulin concentrations were sufficient to maintain follicle development in all treatments.

A possible explanation for the stimulatory effect of CaPFA supplementation on number of small follicles is that a certain threshold fatty acid supply (between 35 and $41 \mathrm{~g} / \mathrm{kg}$ of $\mathrm{DM}$ ) is required for normal follicle and CL development. The mode of action for this effect could be supply of cholesterol for progesterone synthesis (Staples et al., 1998), which is supported by the greater circulating progesterone concentrations in cows fed supplementary fatty acids.

The lack of dietary influence on GH, together with the observation of Gong et al. (1997) that GH increased follicle numbers only in animals with high insulin, supports the suggestion that $\mathrm{GH}$ is not directly involved in the physiological mechanism underlying the nutritional influence on ovarian function in cattle (Webb et al., 2004).

The results of this experiment indicate that levels of CaPFA supplementation greater than $15 \mathrm{~g} / \mathrm{kg}$ of DM can reduce plasma insulin. Although reduced insulin was not detrimental for the production and reproduction measures in the current study, previous studies suggest that low plasma insulin might be detrimental to resumption of estrous cycles postpartum. Yet, some elements of the reproductive system might benefit from fatty acid supplementation. Fouladi-Nashata et al. (2007) found that the proportion of oocytes developing to the blastocyst stage following in vitro fertilization was greater in cows fed a high-fat diet (equivalent to diet 5) compared with a low-fat diet (equivalent to diet 2). Staples and Thatcher (2005) reviewed the effects of 
fatty acids on reproduction in dairy cows and found evidence that supplementation with polyunsaturated fatty acids (specifically linoleic, linolenic, eicosapentaenoic, and docosahexanoic acids) might target specific reproductive tissues to potentially improve reproductive function. They concluded that mechanisms had not been adequately explained, but might involve improving progesterone status, development of larger ovulatory follicles, or partial suppression of prostaglandin secretion from the uterus around the time of embryo implantation. This suggests that fatty acid effects on reproduction vary with stage of the reproductive cycle and emphasizes the need to consider both metabolic and nutrient supply effects of fatty acids on a temporal basis (Garnsworthy et al., 2008b) when designing diets to optimize milk production and fertility.

\section{CONCLUSIONS}

This experiment provides further evidence that plasma insulin can be manipulated by fatty acid supplementation, suggesting that increasing fatty acid supplementation decreases insulin independently of changes in dietary starch concentration, and that glucagon responses depend on dietary starch rather than fatty acids. The critical upper threshold for avoiding plasma insulin depression in cows at the start of the breeding period was between 47 and $53 \mathrm{~g}$ of total fat/ $\mathrm{kg}$ of DM, which is slightly higher than the threshold of $44 \mathrm{~g}$ of total fat $/ \mathrm{kg}$ of DM observed previously where increasing levels of fatty acid supplementation were accompanied by decreasing starch concentrations.

There was little variation in reproductive measures among dietary treatments containing supplemental fatty acids. But, the results suggest that a small amount of supplemental CaPFA could increase the number of small ovarian follicles and that higher levels of supplemental CaPFA could increase plasma progesterone concentrations.

\section{ACKNOWLEDGMENTS}

This study was part of Project LK0646 in the LINK Sustainable Livestock Production program, which was funded by The Scottish Executive Environment and Rural Affairs Department (SEERAD, Edinburgh, UK), ABNA Ltd. (Peterborough, UK), BOCM PAULS Ltd. (Ipswich, UK), and Provimi Ltd. (Sint-StevensWoluwe, Belgium). The following people served on the Programme Management Committee and made valuable contributions to the design and interpretation of the experiment: J. Newbold (Provimi), M. Marsden (ABNA), S. Richards (Provimi), A. Henderson (BOCM PAULS), P. Thomas (Artilus Ltd., UK), D. Armstrong
(Roslin Institute, Edinburgh, UK), A. Flint (Univ. Nottingham, UK), D. Garwes (Department for Environment, Food and Rural Affairs), and D. Leaver (Royal Agricultural College). We would like to thank the following people for technical assistance: H. Russell (Univ. Nottingham), J. Gong (Roslin Inst.), G. Baxter (Roslin Inst.), M. Mitchell (Univ. Nottingham), N. Armstrong (Univ. Nottingham), D. Scholey (Univ. Nottingham), M. Hunter (Univ. Nottingham), D. Whitaker (Univ. Edinburgh), and C. Smith (National Milk Records). Statistical advice was provided by J. Craigon (Univ. Nottingham).

\section{REFERENCES}

Allen, M. S. 2000. Effects of diet on short-term regulation of feed intake by lactating dairy cattle. J. Dairy Sci. 83:1598-1624.

Beam, S. W., and W. R. Butler. 1997. Energy balance and ovarian follicle development prior to the first ovulation postpartum in dairy cows receiving three levels of dietary fat. Biol. Reprod. $56: 133-142$

Burns, D. S., F. Jimenez-Krassel, J. L. H. Ireland, P. G. Knight, and J. J. Ireland. 2005. Numbers of antral follicles during follicular waves in cattle: Evidence for high variation among animals, very high repeatability in individuals, and an inverse association with serum follicle-stimulating hormone concentrations. Biol. Reprod. 73:54-62.

Choi, B. R., and D. L. Palmquist. 1996. High fat diets increase plasma cholecystokinin and pancreatic polypeptide, and decrease plasma insulin and feed intake in lactating cows. J. Nutr. 126:29132919.

Choi, B. R., D. L. Palmquist, and M. S. Allen. 2000. Cholecystokinin mediates depression of feed intake in dairy cattle fed high fat diets. Domest. Anim. Endocrinol. 19:159-175.

Fouladi-Nashta, A. A., C. G. Gutierrez, J. G. Gong, P. C. Garnsworthy, and R. Webb. 2007. Impact of dietary fatty acids on oocyte quality and development in lactating dairy cows. Biol. Reprod. 77:9-17.

Garnsworthy, P. C., A. Lock, G. E. Mann, K. D. Sinclair, and R. Webb. 2008a. Nutrition, metabolism and fertility in dairy cows 1. Dietary energy source and ovarian function. J. Dairy Sci. 91:3814-3823.

Garnsworthy, P. C., K. D. Sinclair, and R. Webb. 2008b. Integration of physiological mechanisms that influence fertility in dairy cows. Animal 2:1144-1152.

Gong, J. G., G. Baxter, T. A. Bramley, and R. Webb. 1997. Enhancement of ovarian follicular development in heifers by treatment with recombinant bovine somatotropin: A doseresponse study. J. Reprod. Fertil. 110:91-97.

Gong, J. G., W. J. Lee, P. C. Garnsworthy, and R. Webb. 2002. Effect of dietary-induced increases in circulating insulin concentrations during the early postpartum period on reproductive function in dairy cows. Reproduction 123:419-427.

Gutierrez, C. G., J. G. Gong, T. A. Bramley, and R. Webb. 2006 Selection on predicted breeding value for milk production delays ovulation independently of changes in follicular development, milk production and body weight. Anim. Reprod. Sci. 95:193205.

Gutierrez, C. G., J. Oldham, T. A. Bramley, J. G. Gong, B. K Campbell, and R. Webb. 1997. The recruitment of ovarian follicles is enhanced by increased dietary intake in heifers. J. Anim. Sci. $75: 1876-1884$

Jenkins, T. C. 2003. Fats and protected fats. Pages 997-1003 in Encyclopedia of Dairy Sciences. Vol. 2. H. Roginski, J. W. Fuquay, and P. F. Fox, ed. Academic Press, London, UK. 
Lucy, M. C., J. D. Savio, L. Badinga, R. L. De La Sota, and W. W. Thatcher. 1992. Factors that affect ovarian follicular dynamics in cattle. J. Anim. Sci. 70:3615-3626.

Lucy, M. C., C. R. Staples, F. M. Michel, and W. W. Thatcher. 1991a Energy balance and size and number of ovarian follicles detected by ultrasonography in early postpartum dairy cows. J. Dairy Sci. 74:473-482.

Lucy, M. C., C. R. Staples, F. M. Michel, and W. W. Thatcher. 1991b. Effect of feeding calcium soaps to early postpartum dairy cows on plasma prostaglandin $\mathrm{F} 2 \alpha$, luteinizing hormone, and follicular growth. J. Dairy Sci. 74:483-489.

Oldick, B. S., C. R. Staples, W. W. Thatcher, and P. Gyawu. 1997. Abomasal infusion of glucose and fat-Effect on digestion, production, and ovarian and uterine function of cows. J. Dairy Sci. 80:1315-1328.

Staples, C. R., J. M. Burke, and W. W. Thatcher. 1998. Influence of supplemental fats on reproductive tissues and performance of lactating cows. J. Dairy Sci. 81:856-871.

Staples, C. R., and W. W. Thatcher. 2005. Effects of fatty acids on reproduction of dairy cows. Pages 229-256 in Recent Advances in Animal Nutrition - 2005. P. C. Garnsworthy and J. Wiseman, ed. Nottingham University Press, Nottingham, UK.

Webb, R., P. C. Garnsworthy, J. G. Gong, and D. G. Armstrong. 2004. Control of follicular growth: Local interactions and nutritional influences. J. Anim. Sci. 82(E Suppl.):E63-E74. 